\title{
Nuclear Cataract
}

National Cancer Institute

\section{Source}

National Cancer Institute. Nuclear Cataract. NCI Thesaurus. Code C135176.

A type of cataract that forms deep in the central zone (nucleus) of the lens. Nuclear cataracts are usually associated with aging. 